\title{
KELOMPOK USAHA FOTOCOPY DAN KOMPUTER DI KAMPUS UNSRAT MANADO
}

\author{
Christine Takarina Meitty Manoppo \\ Program Studi Pendidikan Teknologi dan Kejuruan, Fakultas Teknik, \\ Universitas Negeri Manado \\ takarinamanoppo@gmail.com
}

\begin{abstract}
Abstrak
Kelurahan Kleak adalah tempat yang strategis untuk melaksanakan berbagai kegiatan usaha. Sekitar 30-35 persen penduduk kelurahan Kleak tidak memiliki pekerjaan tetap, memiliki tingkat kesejahteraan menengah dan paspasan. Sekitar 65-70 persen memiliki pekerjaan tetap, 30 persen dari mereka memiliki modal untuk menciptakan peluang usaha seperti tempat kost, laundry, rumah makan, cafe/kantin, rental, fotocopy dan komputer. Masalahnya Keterampilan yang dimiliki baik oleh pekerja dan masyarakat tidak sesuai dengan yang dibutuhkan oleh kelompok usaha yang dimaksud (kelompok mitra). Tim IbM dengan kelompok mitra " Mars fotocopy dan computer", memberikan pelatihan penggunaan aplikasi ms word, photoshop dan coraldraw agar bisa mendisain undangan, banner dan baliho, dengan menggunakan metode problem solving, berupa metode ceramah, diskusi dan demonstrasi. Pelaksanaan kegiatan pelatihan ini secara keseluruhan berhasil dengan baik, dan menunjukkan bahwa tujuan dari pelaksanaan pelatihan ini tercapai dengan baik. Dan mendapat respon yang positif untuk ditindaklanjuti pada waktu yang akan datang.
\end{abstract}

Kata Kunci: Ms word, photoshop, coreldraw.

\section{PENDAHULUAN}

\section{Analisis Situasi}

Masyarakat di kelurahan Kleak, sebagian besar memiliki penduduk yang tidak tetap (pendatang), data yang ada menunjukkan bahwa Kelurahan Kleak, memiliki jumlah penduduk 5.178 jiwa dengan jumlah KK 1.538 yang tersebar di 6 lingkungan. Dari sisi mata pencaharian PNS memiliki ranking tertinggi dan terendah adalah buruh dan tukang yang tersebar di enam lingkungan. Dalam upaya meningkatkan kesejahteraan hidup yang merupakan tuntutan, maka masyarakat kelurahan Kleak berpeluang untuk memperbaiki kualitas hidupnya melalui berbagai usaha agar memperoleh penghasilan yang layak. Ada banyak pilihan yang bisa mereka lakukan, apakah menjadi wirausaha bagi yang mempunyai banyak modal, ataupun menawarkan jasa kepada pemilik modal bagi yang punya keterampilan. Di bawah ini adalah foto situasi yang setiap hari terjadi di kelurahan Kleak tepatnya di Kampus Unsrat Manado (Gerbang Bagian Barat).

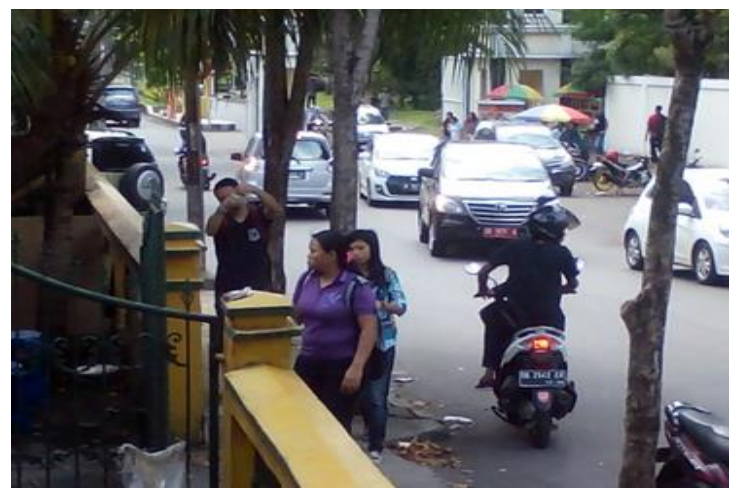

Gambar 1. Aktivitas Kelurahan Kleak, sekitar Kampus UNSRAT. 
Kelurahan Kleak merupakan tempat yang sangat cocok dan strategis untuk melaksanakan berbagai kegiatan usaha seperti tempat penginapan, tempat kost, laundry, rumah makan, cafe/kantin, rental, fotocopy dan komputer. Seperti yang terlihat dalam gambar, dapat dipastikan bahwa antara masyarakat yang tinggal di kelurahan Kleak dengan para mahasiswa, pegawai dan dosen yang beraktivitas di Kampus Unsrat memiliki ketergantungan satu sama lainnya.

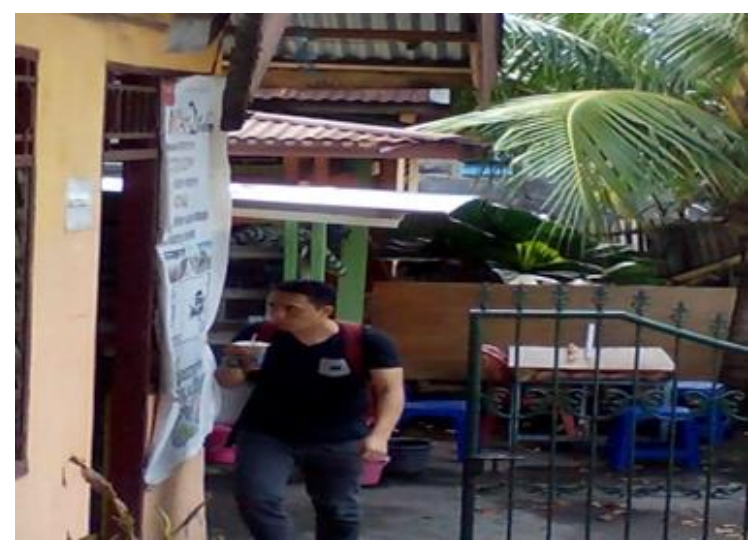

Gambar 2. Gambaran aktivitas usaha fotocopy.

Dari data kependudukan yang diuraikan sebelumnya menunjukan bahwa ada sekitar 30-35 persen penduduk kelurahan Kleak tidak memiliki pekerjaan tetap, sehingga memiliki tingkat kesejahteraan menengah dan paspasan. Mereka itu adalah masyarakat usia produktif yang belum memiliki pekerjaan tetap seperti tukang ojek, pembantu rumah tangga mingguan/harian, dan lain lain, termasuk kelompok usia produktif berstatus siswa/mahasiswa tetapi belum bisa atau tidak dapat melanjutkan sekolah/ kuliahnya karena masalah ekonomi, ataupun kawin muda. Dan kelompok tersebut, 60 persen dari mereka tidak memiliki keterampilan khusus.

Disisi yang lain penduduk yang mempunyai pekerjaan tetap, sesuai data sebelumnya ada sekitar 65-70 persen memiliki pekerjaan tetap, dan 30 persen dari mereka memiliki modal untuk menciptakan peluang usaha. Dan peluang yang dimaksud dimanfaatkan oleh mereka untuk menyediakan berbagai usaha yang merupakan kebutuhan konsumen mulai dari kebutuhan sandang, pangan dan papan.

Permasalahnya sekarang adalah tenaga yang memiliki keterampilan tidak banyak. Keterampilan yang dimiliki tidak sesuai dengan apa yang dibutuhkan. Apapun alasannya yang pasti setiap usaha ataupun lapangan pekerjaan, akan berkembang dengan baik jika memiliki tenaga kerja yang baik, trampil dan memiliki pengetahuan yang memadai tentang bidang pekerjaannya. Sebagai contoh, usaha fotocopy yang di tekuni oleh sdr. Edwin Monoarfa, bersama teman-teman kurang lebih 10 tahun. Usaha ini oleh pemiliknya diberi nama Mars Fotocopy dan Komputer, (sebagai kelompok Mitra). Usaha Mars Fotocopy dan Komputer, selama ini melayani jasa fotocopy, penjilidan dan fasilitas membuat baliho dan banner sedikit kendala. Orderan banyak akan tetapi tenaga trampil kurang. Padahal jika diberi perhatian oleh pemilik dan sedikit diberi keterampilan kepada para pekerja ataupun 
bagi mereka yang berminat, maka akan ada tenaga trampil (baik pekerja dari kelompok usaha ataupun para pekerja yang berasal dari luar/masyarkat sekitar) bisa dipastikan usaha dari kelompok mitra ini akan berkembang menjadi lebih baik. Omset meningkat, penghasilan meningkat dan lebih dari itu telah membuka lapangan kerja baru bagi yang membutuhkan.

Dari hasil wawancara tim IbM dengan pemilik mitra, diperoleh kesepakatan bahwa tim IbM dari Unima akan memberikan pelatihan keterampilan menggunakan aplikasi corell draw dan photoshop mendisain undangan, banner dan baliho.

\section{Permasalahan Mitra}

Usaha fotocopy dan Komputer, dari kelompok mitra memiliki masalah sebagai berikut. Kelompok mitra tidak banyak memiliki pekerja yang memiliki keterampilan sesuai dengan apa yang dibutuhkan. Padahal apabila tenaga kerja cukup dan memadai, usaha ini masih bisa dikembangkan sesuai kebutuhan. Nama usaha Mars Fotocopy dan Komputer. Sebagai pengelola adalah Edwin Monoarfa, usia 30 tahun, masih singel/belum menikah. Bersama dengan 3 rekannya menjalankan usaha ini sejak 10 tahun yang lalu. Lokasi Kelurahan Kleak lingk. VI.

Kendala yang dihadapi adalah kurangnya tenaga trampil. Usaha fotocopy dan Komputer yang selama ini melayani jasa fotocopy, penjilidan dan fasilitas membuata banner dan undangan menggunakan aplika- si corall draw dan photoshop mengalami sedikit kendala. Banyak pelanggan, tetapi tenaga trampil kurang. Padahal jika diberi perhatian oleh pemilik dan sedikit diberi keterampilan kepada para pekerja, akan banyak tenaga trampil yang tersedia. Dapat dipastikan usaha dari kelompok mitra ini akan berkembang menjadi lebih baik, omset meningkat, penghasilan meningkat dan lebih dari itu telah membuka lapangan kerja baru bagi yang membutuhkan.

Masalah yang dihadapi oleh kelompok siswa/mahasiswa yang belum bisa atau tidak dapat melanjutkan sekolah/kuliahnya, kita sebut dengan pemuda putus sekolah. Kelompok ini, tersebar di seputaran kampus memiliki keterampilan yang minim, sehingga sulit memperoleh pekerjaan. Akibatnya pengangguran ada dimana mana dan sulit dibendung. Oleh pemerintah, masalah pengangguran yang diakibatkan oleh anakanak putus sekolah ini diantisipasi dengan membekali mereka dengan knowledge dan skill agar bisa mandiri dan berwirausaha. Mereka perlu dibekali agar bisa memperoleh pengetahuan dan keterampilan. Selain itu mereka dapat berwirausaha (usaha kecil, menengah), sebagian dapat menjadi tenaga kerja yang baik. Dengan demikian dapat menciptakan lapangan kerja yang baru dan merikrut tenaga kerja yang lebih banyak.

Masalah pengangguran tadi mengakibatkan banyak hal, dan berdampak pada masyarakat. tuntutan ekonomi yang tinggi, 
mempengruhi stress, dan akhirnya meningkatkan kejahatan, seperti pencurian, perampokan, kekerasan, dan perkelahian. Untuk itu anak-anak putus sekolah maupun putus kuliah perlu dibekali dengan keterampilan yang cukup agar selain dapat meningkatkan kesejahteraan dan pendapatan keluarga juga mengurangi stres di masyarakat. Apabila kegiatan ini dilaksanakan sesuai sasaran dapat dipastikan, pengangguran dan kemiskinan dapat dicegah.

\section{METODE PELAKSANAAN}

Secara garis besar tahapan metode dan pendekatan yang telah disepakati bersama dalam proses realisasi IbM adalah melalui problem solving, merupakan cara memberikan pengetahuan dengan menstimulasi pengusaha rental computer dan staf serta pemuda putus sekolah untuk memperhatikan, dan mengupayakan secara bersama-sama dengan tim IbM untuk memecahkan masalah yang dihadapi oleh mitra dengan menggunakan metode ceramah, diskusi dan demonstrasi serta partisipasi aktif dari mitra.

\section{Diskusi}

Pelaksanaan kegiatan IbM rental komputer ini diawali dengan wawancara antara pemilik usaha dengan tim IbM dari PT. Unima. Setelah itu tim melaksanakan konfirmasi dengan para pemerintah Kelurahan Kleak manado menyangkut kebutuhan yang ada di masyarakat sehubungan dengan keberadaan kelompok usaha yang dimaksud.
Ternyata dari pihak mitra menerima Ipteks dari Perguruan Tinggi Unima dan membuat kesepakatan.

\section{Ceramah}

Menyampaikan materi melalui ceramah menyangkut materi Desain dan penggunaan aplikasi Microsoft office, corall Draw dan materi manajemen.

\section{Tutorial dan Praktik}

Tutorial dilakukan berkaitan dengan materi penggunaan aplikasi Microsoft office, corall Draw, dan Photoshop. Untuk praktik, dilakukan dalam mendesain dan menggunakan aplikasi.

\section{Metode Tepat Guna}

Untuk mengatasi masalah yang dihadapi oleh pengusaha dan masyarakat lainnya, maka metode pendekatan yang dilakukan adalah metode "tepat guna" aplikasi ilmu pengetahuan dan teknologi sesuai dengan kebutuhan kelompok mitra dengan pendekatan partisipatif dan metode demonstrasi dimana mereka langsung melihat, berbuat, dan menerapkan secara bersama-sama sesuai dengan tahap-tahap kegiatan yang akan dilaksanakan.

\section{HASIL DAN PEMBAHASAN}

Kegiatan ini dilaksanakan pada hari jumat dan sabtu pada tanggal 4 dan 5 Agustus 2017 yang dimulai pada setiap jam 
18.00-22.00 bertempat di The mukaruma café n resto Kampus Unsrat Kleak Manado.

Target peserta 25 orang yang terdiri dari siswa putus sekolah, mahasiswa putus kuliah, Mahasiswa aktif tapi berminat untuk mengembangkan diri. Namun karena berbagai halangan dan aktifitas peserta yang beragam maka yang aktif berjumlah 23 orang. Sebelum kegiatan tatap muka dengan peserta, Instruktur yang adalah pelaksana kegiatan pengabdian ini dibantu dengan tim yang lain membagi tugas sesuai bidang masing-masing.

Dengan demikian pelaksanaan kegiatan pelatihan ini diperoleh hasil sebagai berikut: Kelompok pelatihan menggunakan aplikasi Microsoft word yang berjumlah 5 peserta semuanya memperoleh hasil dengan kategori sangat baik, sesuai dengan tujuan dari penggunaan aplikasi ini membuat dokumen boleh tercapai. Kelompok pelatihan menggunakan aplikasi Photoshop dari 6 peserta, 4 mendapat hasil dengan kategori sangat baik dan 2 peserta mendapat hasil dengan kategori baik, yang berarti tujuan penggunaan aplikasi ini merekayasa (edit, menambah, mengubah foto) tercapai. Kelompok pelatihan aplikasi coral draw dari 12 peserta, 5 peserta mendapat hasil dengan kategori sangat baik, 7 dengan kategori baik. Hal ini berati bahwa tujuan dari penggunaan aplikasi ini, membuat baner, baliho dan mendisain undangan sederhana boleh tercapai.

Tabel 1. Data hasil kegiatan.

\begin{tabular}{|c|c|c|c|c|c|}
\hline \multirow[t]{2}{*}{ No. } & \multirow[t]{2}{*}{ Materi Pelatihan } & \multirow{2}{*}{$\begin{array}{l}\text { Jumlah } \\
\text { Peserta }\end{array}$} & \multicolumn{3}{|c|}{ Hasil Pelatihan } \\
\hline & & & $\begin{array}{c}\text { Kurang } \\
\text { Baik }\end{array}$ & Baik & $\begin{array}{c}\text { Sangat } \\
\text { Baik }\end{array}$ \\
\hline 1 & Aplikasi Word & 5 & - & - & 5 \\
\hline 2 & Aplikasi Photoshop & 6 & - & 2 & 4 \\
\hline 3 & Aplikasi CoralDraw & 12 & - & 7 & 5 \\
\hline \multicolumn{2}{|r|}{ Total } & 23 & - & $39 \%$ & $61 \%$ \\
\hline 4 & Manajemen & 23 & - & 12 & 11 \\
\hline \multicolumn{2}{|r|}{ Total } & 23 & - & $52 \%$ & $48 \%$ \\
\hline
\end{tabular}

Berdasarkan hasil kegiatan pengabdian dapatlah dikatakan bahwa kegiatan ini mendapat respon yang positif dari para peserta, termasuk pemerintah dan masyarakat. Dari hasil pengamatan selama melaksanakan kegiatan ini, para peserta terlihat sangat antusias mengikuti kegiatan, dan hasilnya juga sangat baik. .Namun demikian tak bisa dipungkiri dalam pelaksanaannya kegiatan ini ditemukan sedikit masalah berupa waktu pelaksanaan yang kurang tepat yang rencananya dilaksanakan pada jam 16.0020.00. bergeser ke jam 18.00-22.00 malam. Yang kedua dimana peserta tidak memiliki kemampuan awal yang sama dikarenakan berasal dari latar belakang pendidikan yang berbeda sehingga para instruktur menemui sedikit kesulitan untuk memberikan materi. 
Namun semuanya bisa diatasi berkat kerjasama dan semangat yang tinggi dari peserta.
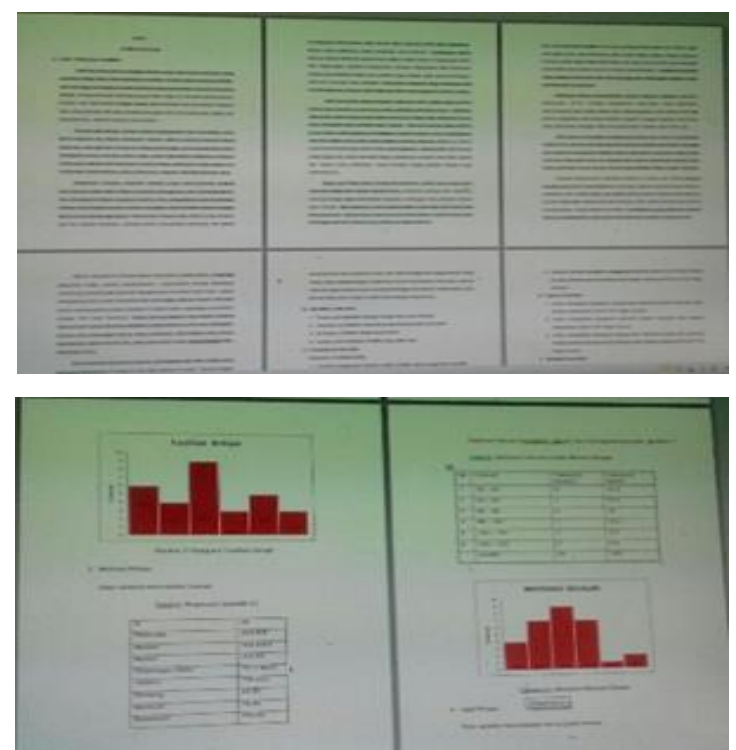

Gambar 3. Contoh luaran pelatihan MS-Word..
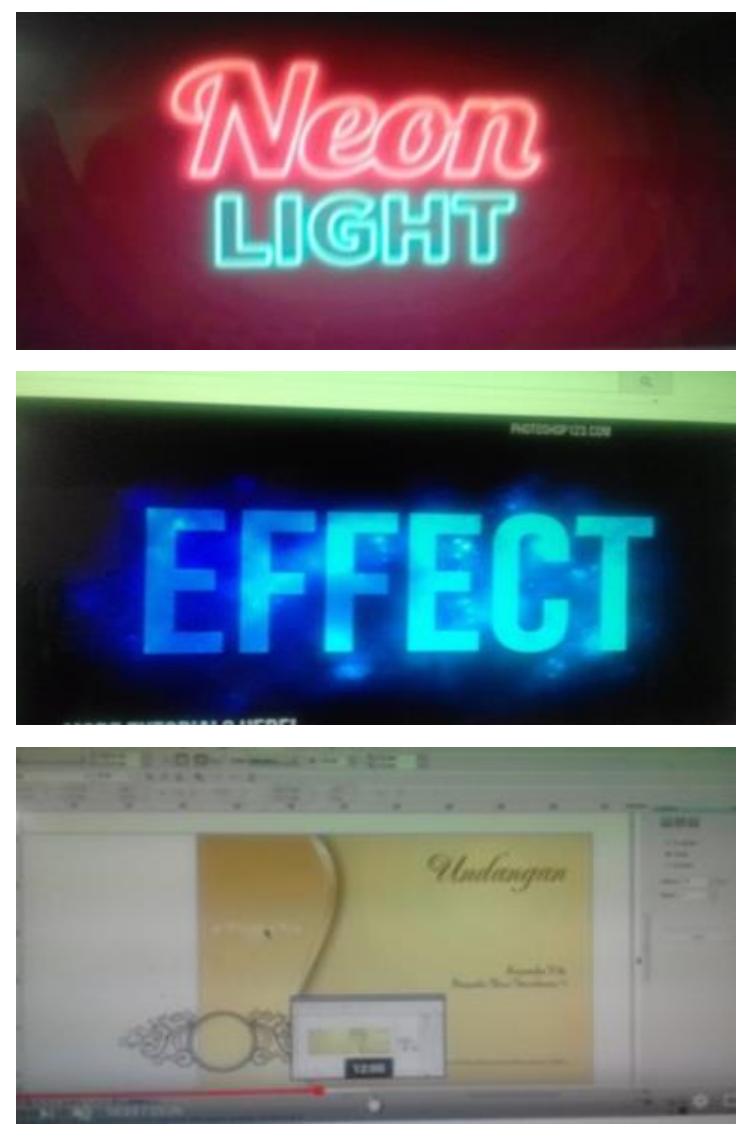

Gambar 4. Contoh luaran pelatihan coreldraw.
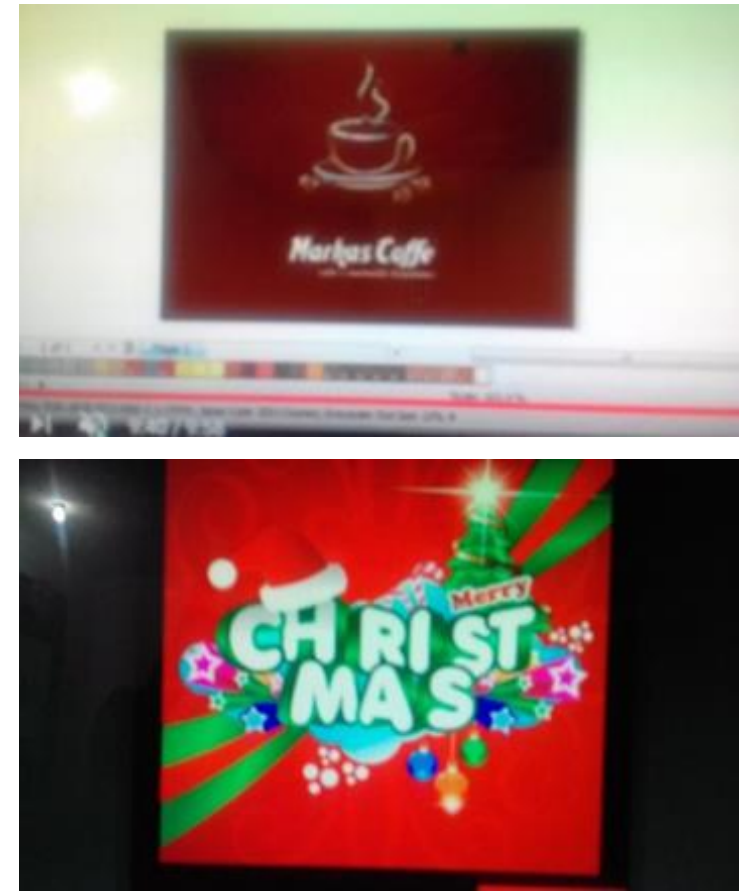

Gambar 4 (lanjutan). Contoh luaran pelatihan coreldraw.
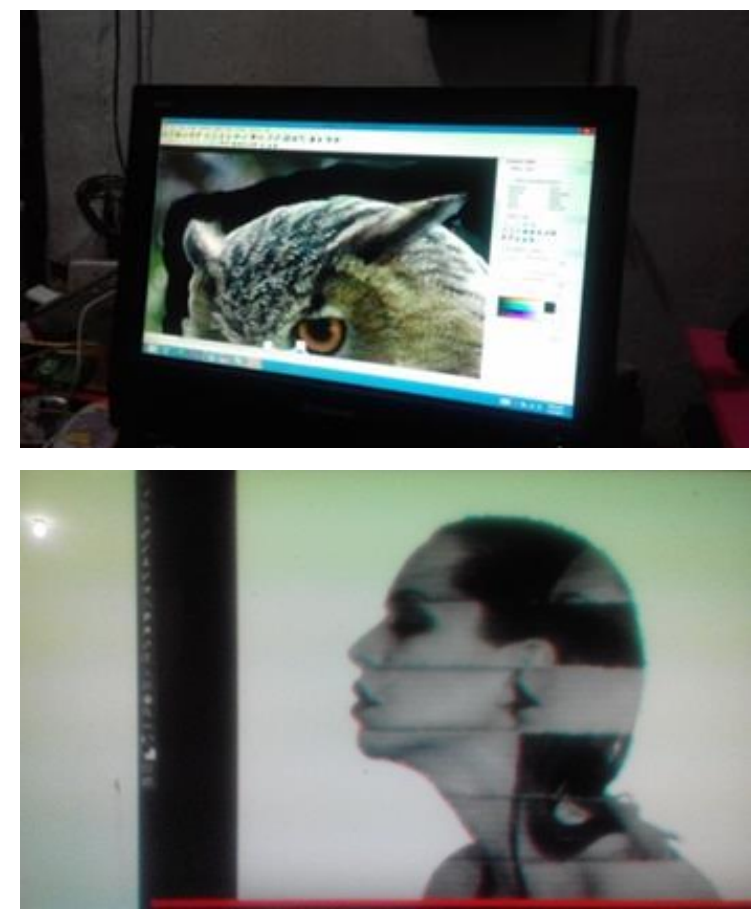

Gambar 5. Contoh luaran hasil penelitian photoshop.

\section{KESIMPULAN DAN SARAN}

Dapat disimpulkan bahwa Pelaksanaan kegiatan pelatihan ini secara keseluruhan 
telah berhasil dengan baik. Dari 3 kelompok yang mendalami 3 aplikasi yang di latih, 61 \% mendapat hasil dengan kategori yang sangat baik dan $39 \%$ dengan hasil kategori baik, Hal ini menunjukkan bahwa tujuan dari pelaksanaan pelatihan ini tercapai dengan baik.Tanggapan terhadap pelaksanaan kegiatan pelatihan ini sangat baik. Hal ini dapat dilihat dari idikator keikutsertaan peserta mencapai 92\% dari target, dan selama kegiatan berlangsung mereka sangat antusias mengikuti kegiatan dari awal sampai akhir kegitan.

Kegiatan ini mendapat respon yang positif, tentunya hal ini bisa ditindaklanjuti waktu berikutnya, dengan aplikasi yang lain disesuaikan dengan kebutuhan mitra dan masyarat terutama kelompok pemuda/mahasiswa putus kuliah, agar nantinya mereka memiliki ketrampilan yang baik khususnya untuk kelompok pemuda/mahasiswa putus kuliah, untuk bekal hidupnya nanti.

\section{KEPUSTAKAAN}

Lily Puspa Dewi, 2013 Microsoft Word 2010 Tutorial Pelatihan Komputer; Pusat Komputer Universitas Kristen Petra Surabaya,

http://staff.uny.ac.id/sites/default/files/tm p/MODUL CORELDRAW.pdf; Modul Pelatihan Disain Grafis CoralDraw;

http://arwan.lecture.ub.ac.id/files/2011/0 9/f 86 modul-adope-photoshop-cs3.pdf' Modul Adope Photoshop CS 
Jurnal ABDIMAS, Vol. 11, No. 3, Desember 2018

ISSN: 1979-0953 | e-ISSN: 2598-6066 